Article

\title{
Elevated Preoperative Serum Alanine Aminotransferase/Aspartate Aminotransferase (ALT/AST) Ratio Is Associated with Better Prognosis in Patients Undergoing Curative Treatment for Gastric Adenocarcinoma
}

\author{
Shu-Lin Chen ${ }^{\dagger}$, Jian-Pei Li ${ }^{\dagger}$, Lin-Fang Li, Tao Zeng and Xia He * \\ State Key Laboratory of Oncology in South China, Collaborative Innovation Center for Cancer Medicine, \\ Sun Yat-sen University Cancer Center, Guangzhou 510060, China; chenshl@sysucc.org.cn (S.-L.C.); \\ lijianpeisysucc@sina.com (J.-P.L.); linlinf851@aliyun.com (L.-F.L.); liu81219355@163.com (T.Z.) \\ * Correspondence: lin81219359@163.com; Tel./Fax: +86-20-8734-3438 \\ + These authors contributed equally to this work.
}

Academic Editor: William Chi-shing Cho

Received: 10 April 2016; Accepted: 6 June 2016; Published: 9 June 2016

\begin{abstract}
The level of anine aminotransferase/aspartate aminotransferase (ALT/AST) ratio in the serum was often used to assess liver injury. Whether the ALT/AST ratio (LSR) was associated with prognosis for gastric adenocarcinoma (GA) has not been reported in the literature. Our aim was to investigate the prognostic value of the preoperative LSR in patients with GA. A retrospective study was performed in 231 patients with GA undergoing curative resection. The medical records collected include clinical information and laboratory results. We investigated the correlations between the preoperative LSR and overall survival (OS). Survival analysis was conducted with the Kaplan-Meier method, and Cox regression analysis was used to determine significant independent prognostic factors for predicting survival. A $p$ value of $<0.05$ was considered to be statistically significant. A total of 231 patients were finally enrolled. The median overall survival was 47 months. Multivariate analysis indicated that preoperative LSR was an independent prognostic factor in GA. Patients with LSR $\leqslant 0.80$ had a greater risk of death than those with LSR $>0.80$. The LSR was independently associated with OS in patients with GA (hazard ratio: 0.610 ; 95\% confidence interval: $0.388-0.958$; $p=0.032$ ), along with tumor stages (hazard ratio: 3.118; 95\% confidence interval: 2.044-4.756; $p<0.001$ ) and distant metastases (hazard ratio: 1.957; 95\% confidence interval: $1.119-3.422 ; p=0.019$ ). Our study first established a connection between the preoperative LSR and patients undergoing curative resection for GA, suggesting that LSR was a simple, inexpensive, and easily measurable marker as a prognostic factor, and may help to identify high-risk patients for treatment decisions.
\end{abstract}

Keywords: ALT / AST ratio (LSR); gastric adenocarcinoma; survival; prognosis

\section{Introduction}

Stomach cancer, or gastric cancer (GC), is a disease in which malignant cells form in the lining of the stomach. The most common type is called adenocarcinoma (GA). Other types of gastric cancer are gastrointestinal carcinoid tumors, gastrointestinal stromal tumors, and lymphomas. GC is one of the most prevalent malignant diseases and the second-most common cause of cancer-related death in the world. Over $70 \%$ of new cases and deaths occur in developing countries, with the majority in China [1]. The ratio of men to women is about 2:1. The highest incidence-up to 69 cases per 100,000 people per year-is in men in Northeast Asia [2]. Over the past couple of decades, although advances have been seen in surgical techniques and adjuvant chemotherapy, the prognosis remains dismal [3]. To prolong 
the survival of GA patients, sensitive and specific factors for classifying cancer risk and predicting survival are always desired in clinics to select patients for tailor treatment.

Serum alanine aminotransferase (ALT) and aspartate aminotransferase (AST) are the main circulating enzymes in the body, are synthesized by the liver, and have half-lives of approximately 18 and $36 \mathrm{~h}$ in a healthy young adults, respectively [4]. Transaminases are commonly considered as liver function tests; however, given that, in addition to liver, AST is produced in other tissues, such as heart, muscles, and so on [5,6]. Serum ALT activity has long been used as an inflammatory marker to assess liver injury related to multiple etiologies including hepatitis, tumors, liver cirrhosis, and alcohol consumption, and the level of ALT/AST ratio (LSR) in the serum has been generally accepted as a better predictor of liver injury [7]. Some studies have confirmed that the indexes of liver function could become better prognostic biomarkers [8-12]. However, there are no studies that have evaluated the association between the preoperative serum LSR and survival in GA. Thus, the prognostic value of the LSR in patients with GA is not clear. In this study, we performed a large-scale retrospective cohort analysis to examine the association between LSR and survival in GA patients who are undergoing curative treatment.

\section{Results}

\subsection{Patients}

A total of 231 eligible patients were identified from January 2008 to December 2015. The clinicopathologic characteristics of the 231 GA patients in this study are described in Table 1. There were 160 men $(69.3 \%)$ and 71 women $(30.7 \%)$ with a median age of 56 years (range, 23-79 years). Of these, $29(12.6 \%)$ were stage I, $52(22.5 \%)$ were stage II, $94(40.7 \%)$ were stage III, and $56(24.2 \%)$ were stage IV. At the time of last follow-up, the median overall survival (OS) was 47 months.

Table 1. Clinical and laboratory characteristics of 231 patients associated with overall survival (OS).

\begin{tabular}{|c|c|c|c|}
\hline Patient Characteristics & No. of Patients (\%) & OS (Months) Mean (95\% CI) & $p$-Value Log-Rank \\
\hline \multicolumn{4}{|c|}{ Sex } \\
\hline Male & $160(69.3 \%)$ & $62.5(57.0-67.9)$ & \multirow[b]{2}{*}{0.478} \\
\hline Female & $71(30.7 \%)$ & $59.7(51.4-68.1)$ & \\
\hline \multicolumn{4}{|c|}{ Age (years) } \\
\hline$\leqslant 56$ & $118(51.1 \%)$ & $64.4(58.2-70.6)$ & \multirow[b]{2}{*}{0.183} \\
\hline$>56$ & $113(48.9 \%)$ & $58.8(52.1-65.6)$ & \\
\hline \multicolumn{4}{|c|}{ Smoking Behaviour } \\
\hline Yes & $64(27.7 \%)$ & $65.5(57.1-73.9)$ & \multirow[b]{2}{*}{0.308} \\
\hline No & $167(72.3)$ & $60.4(54.9-65.8)$ & \\
\hline \multicolumn{4}{|c|}{ Family History } \\
\hline Yes & $23(10.0 \%)$ & $63.3(50.3-76.3)$ & \multirow{2}{*}{0.563} \\
\hline No & $208(90.0 \%)$ & $61.5(56.4-66.4)$ & \\
\hline \multicolumn{4}{|c|}{ Pathological Stage ${ }^{a}$} \\
\hline I & $29(12.6 \%)$ & $86.8(84.4-89.1)$ & \multirow{4}{*}{$<0.001$} \\
\hline II & $52(22.5 \%)$ & $85.9(82.1-89.8)$ & \\
\hline III & $94(40.7 \%)$ & $57.9(50.9-64.9)$ & \\
\hline IV & $56(24.2 \%)$ & $29.6(21.7-37.5)$ & \\
\hline \multicolumn{4}{|c|}{ Lymph Node Metastasis $(\mathrm{N})$} \\
\hline No & $17(7.3 \%)$ & $74.9(62.2-87.6)$ & \multirow{4}{*}{$<0.001$} \\
\hline N1 & $38(16.5 \%)$ & $70.8(60.1-80.5)$ & \\
\hline N2 & $156(67.5 \%)$ & $60.3(54.9-65.8)$ & \\
\hline N3 & $20(8.7 \%)$ & $35.4(19.7-51.1)$ & \\
\hline \multicolumn{4}{|c|}{ Distant Metastases } \\
\hline Yes & $39(16.9 \%)$ & $25.4(17.7-33.2)$ & \multirow{2}{*}{$<0.001$} \\
\hline No & $192(83.1 \%)$ & $68.7(64.1-73.3)$ & \\
\hline
\end{tabular}


Table 1. Cont.

\begin{tabular}{|c|c|c|c|}
\hline Patient Characteristics & No. of Patients (\%) & OS (Months) Mean $(95 \% \mathrm{CI})$ & $p$-Value Log-Rank \\
\hline \multicolumn{4}{|c|}{ Tumor Location $^{\mathrm{a}}$} \\
\hline Upper & $49(21.2 \%)$ & $51.3(41.7-60.8)$ & \multirow{3}{*}{0.062} \\
\hline Middle & $61(26.4 \%)$ & $58.4(49.9-66.9)$ & \\
\hline Lower & $121(52.4 \%)$ & $66.7(60.5-72.9)$ & \\
\hline \multicolumn{4}{|c|}{ Maximun Tumor Diameter $(\mathrm{cm})$} \\
\hline$\leqslant 5$ & $144(62.3 \%)$ & $70.1(64.9-75.4)$ & \multirow{2}{*}{$<0.001$} \\
\hline$>5$ & $87(37.7 \%)$ & $48.1(40.4-55.7)$ & \\
\hline \multicolumn{4}{|c|}{ Serous Infiltration } \\
\hline S0 & $44(19.1 \%)$ & $86.0(81.8-90.1)$ & \multirow{4}{*}{$<0.001$} \\
\hline S1 & $37(16.0 \%)$ & $63.9(52.2-75.5)$ & \\
\hline S2 & $100(43.3 \%)$ & $58.3(51.5-65.2)$ & \\
\hline S3 & $50(21.6 \%)$ & $43.0(33.3-52.7)$ & \\
\hline \multicolumn{4}{|c|}{$\operatorname{ALB}(g / L)$} \\
\hline$\leqslant 35$ & $21(9.1)$ & $41.7(26.9-56.4)$ & \multirow{2}{*}{0.017} \\
\hline$>35$ & $210(90.9 \%)$ & $63.7(58.9-68.4)$ & \\
\hline \multicolumn{4}{|c|}{$\operatorname{ALT}(\mathrm{U} / \mathrm{L})$} \\
\hline$\leqslant 14.6$ & $114(49.4 \%)$ & $59.3(52.9-65.7)$ & \multirow{2}{*}{0.334} \\
\hline$>14.6$ & $117(50.6 \%)$ & $64.1(57.6-70.6)$ & \\
\hline \multicolumn{4}{|c|}{ AST (U/L) } \\
\hline$\leqslant 18.5$ & $116(50.2 \%)$ & $61.1(54.7-67.5)$ & \multirow{2}{*}{0.868} \\
\hline$>18.5$ & $115(49.8 \%)$ & $62.4(55.8-68.9)$ & \\
\hline \multicolumn{4}{|c|}{ LSR $(\mathrm{ALT} / \mathrm{AST})$} \\
\hline$\leqslant 0.80$ & $117(50.6 \%)$ & $55.5(48.9-62.1)$ & \multirow{2}{*}{0.008} \\
\hline$>0.80$ & $114(49.4 \%)$ & $68.2(62.1-74.3)$ & \\
\hline \multicolumn{4}{|c|}{$\mathrm{CRP}(\mathrm{mg} / \mathrm{L})$} \\
\hline$\leqslant 1.56$ & $116(50.2 \%)$ & $65.4(59.2-71.6)$ & \multirow{2}{*}{0.156} \\
\hline$>1.56$ & $115(49.8 \%)$ & $58.0(51.4-64.7)$ & \\
\hline \multicolumn{4}{|c|}{ CA19-9 $(\mathrm{U} / \mathrm{mL})$} \\
\hline$\leqslant 10.97$ & $117(50.6 \%)$ & $66.2(59.8-72.6)$ & \multirow{2}{*}{0.081} \\
\hline$>10.97$ & $114(49.4 \%)$ & $57.5(51.1-64.0)$ & \\
\hline \multicolumn{4}{|c|}{ CA72-4 $(\mathrm{U} / \mathrm{mL})$} \\
\hline$\leqslant 1.8$ & $116(50.2 \%)$ & $69.7(63.7-75.5)$ & \multirow{2}{*}{$<0.001$} \\
\hline$>1.8$ & $115(49.8 \%)$ & $53.9(47.2-60.5)$ & \\
\hline & $\mathrm{CE}$ & $(\mathrm{ng} / \mathrm{mL})$ & \\
\hline$\leqslant 2.17$ & $117(50.6 \%)$ & $66.2(60.0-72.6)$ & \\
\hline$>2.17$ & $114(49.4 \%)$ & $57.2(50.7-63.7)$ & 0.057 \\
\hline & & $(\mathrm{g} / \mathrm{L})$ & \\
\hline$\leqslant 2.82$ & $116(50.2 \%)$ & $66.6(60.4-72.8)$ & \\
\hline$>2.82$ & $115(49.8 \%)$ & $56.8(50.2-63.4)$ & 0.046 \\
\hline & & GPS & \\
\hline 0 & $193(83.6 \%)$ & $64.3(59.4-69.1)$ & \\
\hline 1 & 34 (14.7\%) & $50.1(37.0-63.1)$ & 0.066 \\
\hline 2 & $4(1.7 \%)$ & $43.5(13.8-73.2)$ & \\
\hline & & p53 & \\
\hline 0 & $56(24.2 \%)$ & $59.7(50.2-69.3)$ & \\
\hline+1 & 75 (32.5\%) & $70.3(63.4-77.2)$ & \\
\hline+2 & $34(14.7 \%)$ & $59.0(47.2-70.7)$ & 0.018 \\
\hline+3 & $66(28.6 \%)$ & $52.9(44.1-61.6)$ & \\
\hline & & dype & \\
\hline A & $63(27.3 \%)$ & $57.2(48.3-66.1)$ & \\
\hline $\mathrm{B}$ & $16(6.9 \%)$ & $51.9(37.5-66.2)$ & \\
\hline $\mathrm{AB}$ & $57(24.7 \%)$ & $59.2(50.2-68.2)$ & 0.412 \\
\hline $\mathrm{O}$ & $95(41.1 \%)$ & $66.3(59.3-73.2)$ & \\
\hline
\end{tabular}

\footnotetext{
a According to the 7th UICC-TNM classification; ALT, anine aminotransferase; AST, aspartate aminotransferase; Fbg, Fibrinogen; ALB, albumin; CRP, C-reaction protein; CEA, carcino-embryonic antigen; GPS, Glasgow Prognostic Score.
} 


\subsection{Serum ALT/AST Ratio (LSR) and Survival}

Comparing multiple Kaplan-Meier curves, a significant result from the log rank test indicated that LSR $>0.80$ was associated with better OS ( $p=0.008$; Figure 1D). The mean OS times of patients with LSR $>0.80$ and LSR $\leqslant 0.80$ were 68.2 and 55.5 months, respectively, and one-year survival rate $(p=0.005$; Figure $1 \mathrm{~A})$, three-year survival rate $(p=0.027$; Figure $1 \mathrm{~B})$, and five-year survival rate ( $p=0.015$; Figure 1C) were $95.5 \%$ vs. $84.5 \%, 70.1 \%$ vs. $56.7 \%$, and $67.8 \%$ vs. $52.3 \%$, respectively. In the univariate analysis, variables including pathological stage $(p<0.001)$, lymph node metastasis $(p<0.001)$, distant metastases $(p<0.001)$, location $(p=0.021)$, tumor size $(p<0.001)$, serous infiltration $(p<0.001)$, albumin (ALB) $(p=0.020)$, LSR $(p=0.009)$, CA72-4 $(p=0.001)$, Fibrinogen (Fbg) $(p=0.049)$, Glasgow Prognostic Score (GPS) $(p=0.035)$, and p53 $(p=0.045)$ were significant risk factors for GA survival (Table 2), whereas sex $(p=0.481)$, age $(p=0.187)$, smoking $(p=0.313)$, family history $(p=0.566)$, ALT $(p=0.337)$, AST $(p=0.869)$, C-reaction protein (CRP) $(p=0.160)$, CA19-9 $(p=0.085)$, Carcino-embryonic antigen (CEA) $(p=0.060)$, and ABO blood group $(p=0.115)$ were not (Table 2$)$.
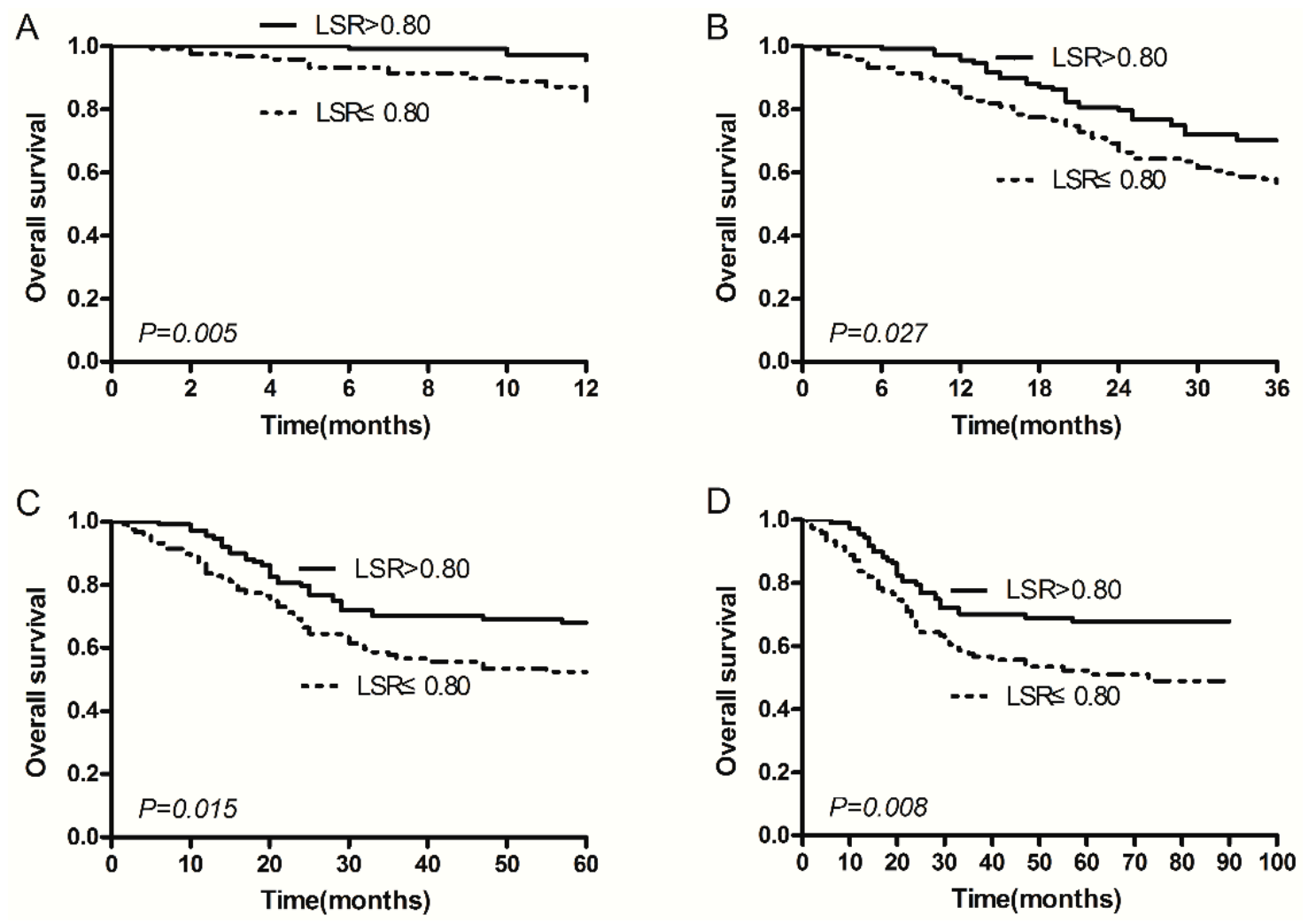

Figure 1. Kaplan-Meier survival curves depict survival curve according to the ALT/AST ratio (LSR). (A) One-year survival according to LSR $>0.80 / \mathrm{LSR} \leqslant 0.80$; (B) three-year survival curve according to LSR > 0.80/LSR $\leqslant 0.80$; (C) five-year survival curve according to LSR > 0.80/LSR $\leqslant 0.80$; and (D) the overall survival (OS) curve according to LSR $>0.80 / \mathrm{LSR} \leqslant 0.80$.

The variables identified as predictors of OS in the univariate analysis were then entered into multivariate Cox regression analysis (Table 2). The results showed LSR (HR 0.610; 95\% CI 0.388-0.958, $p=0.032$ ), TNM stage (HR 3.118; 95\% CI 2.044-4.756, $p<0.001$ ), and distant metastases (HR 1.957; 95\% CI 1.119-3.422, $p=0.019)$ were independent predictive factors for gastric cancer. Patients with $\mathrm{LSR} \leqslant 0.80$ had a greater risk of death than those with LSR $>0.80$. However, lymph node metastasis (HR 0.831; 95\% CI 0.554-1.247; $p=0.371$ ), location (HR 0.852; 95\% CI 0.646-1.123; $p=0.255$ ), tumor size (HR 1.180; 95\% CI 0.752-1.852; $p=0.472$ ), serous infiltration (HR 0.972; 95\% CI 0.708-1.334; $p=0.860$ ), ALB (HR 0.776; 95\% CI 0.247-2.438; $p=0.664)$, CA72-4 (HR 1.479; 95\% CI 0.941-2.325; $p=0.090)$, Fbg 
(HR 1.070; 95\% CI 0.669-1.713; $p=0.778)$, GPS (HR 0.929; 95\% CI 0.431-2.004; $p=0.851$ ), and p53 (HR 1.128; 95\% CI 0.917-1.387; $p=0.255$ ) were not significant predictive factors in multivariate analysis.

Table 2. Univariate and multivariate analysis of OS.

\begin{tabular}{ccccc}
\hline Patient Characteristics & $\begin{array}{c}\text { Univariate Analysis } \\
\text { HR (95\% CI) }\end{array}$ & $p$-Value & $\begin{array}{c}\text { Multivariate Analysis } \\
\text { HR (95\% CI) }\end{array}$ & $p$-Value \\
\hline Sex & $0.853(0.549-1.326)$ & 0.481 & - & - \\
Age (years) & $1.326(0.872-2.018)$ & 0.187 & - & - \\
Smoking Behaviour & $0.777(0.476-1.268)$ & 0.313 & - & - \\
Family History & $0.808(0.391-1.672)$ & 0.566 & - & $<.001$ \\
Pathological Stage & $3.666(2.694-4.988)$ & $<0.001$ & $3.118(2.044-4.756)$ & 0.371 \\
Lymph Node Metastasis (N) & $1.988(1.375-2.874)$ & $<0.001$ & $0.831(0.554-1.247)$ & 0.019 \\
Distant Metastases & $5.286(3.360-8.316)$ & $<0.001$ & $1.957(1.119-3.422)$ & 0.255 \\
Tumor Location & $0.746(0.581-0.957)$ & 0.021 & $0.852(0.646-1.123)$ & 0.472 \\
Maximun Tumor Diameter (cm) & $2.528(1.660-3.848)$ & $<0.001$ & $1.180(0.752-1.852)$ & 0.860 \\
Serous Infiltration & $2.038(1.587-2.618)$ & $<0.001$ & $0.972(0.708-1.334)$ & - \\
ALB (g/L) & $0.485(0.264-0.892)$ & 0.020 & $0.776(0.247-2.438)$ & - \\
ALT (U/L) & $0.814(0.535-1.239)$ & 0.337 & - & - \\
AST (U/L) & $0.965(0.636-1.466)$ & 0.869 & - & - \\
LSR (ALT/AST) & $0.565(0.368-0.868)$ & 0.009 & $0.610(0.388-0.958)$ & 0.032 \\
CRP (mg/L) & $1.351(0.888-2.057)$ & 0.160 & - & 0.155 \\
CA19-9 (U/mL) & $1.454(0.950-2.224)$ & 0.085 & $0.710(0.442-1.139)$ & 0.090 \\
CA72-4 (U/mL) & $2.035(1.318-3.144)$ & 0.001 & $1.479(0.941-2.325)$ & 0.258 \\
CEA (ng/mL) & $1.501(0.983-2.293)$ & 0.060 & $1.331(0.811-2.184)$ & 0.778 \\
Fbg (g/L) & $1.530(1.002-2.338)$ & 0.049 & $1.070(0.669-1.713)$ & 0.851 \\
GPS & $1.565(1.033-2.373)$ & 0.035 & $0.929(0.431-2.004)$ & 0.255 \\
p53 & $1.212(1.005-1.462)$ & 0.045 & $1.128(0.917-1.387)$ & - \\
Blood Type & $0.875(0.741-1.033)$ & 0.115 & & - \\
\end{tabular}

\subsection{The Relationship between the ALT/AST Ratio and Clinicopathologic Characteristics in GA Patients}

Further analysis of the relation among the two groups (LSR $>0.80$ and LSR $\leqslant 0.80$ ) and other prognostic indicators for GA (Table 3). LSR was associated with sex $(p=0.023)$, tumor sizes $(p=0.041)$, $\operatorname{ALB}(p=0.020), \operatorname{ALT}(p<0.001)$, AST $(p=0.004)$, CA19-9 $(p=0.008)$, and CRP $(p=0.025)$. However, LSR did not show any significant association with age $(p=0.148)$, smoking behavior $(p=0.141)$, family history $(p=0.515)$, TNM stage $(p=0.425)$, lymph node metastasis $(p=0.168)$, distant metastases $(p=0.294)$, tumor location $(p=0.247)$, serous infiltration $(p=0.055)$, CA72-4 $(p=0.600)$, CEA $(p=0.793)$, $\operatorname{Fbg}(p=0.694)$, GPS $(p=0.054)$, p53 ( $p=0.075)$, and blood type $(p=0.736)$.

Table 3. Relationship between the LSR and clinicopathologic characteristics.

\begin{tabular}{|c|c|c|c|}
\hline Patient Characteristics & LSR $\leqslant 0.80(n=117)$ & LSR $>0.80(n=114)$ & $p$-Value \\
\hline \multicolumn{4}{|c|}{ Sex } \\
\hline Male & 73 & 87 & \multirow{2}{*}{0.023} \\
\hline Female & 44 & 27 & \\
\hline \multicolumn{4}{|c|}{ Age (years) } \\
\hline$\leqslant 56$ & 54 & 64 & \multirow{2}{*}{0.148} \\
\hline$>56$ & 63 & 50 & \\
\hline \multicolumn{4}{|c|}{ Smoking Behavior } \\
\hline Yes & 90 & 77 & \multirow{2}{*}{0.141} \\
\hline No & 27 & 37 & \\
\hline \multicolumn{4}{|c|}{ Family History } \\
\hline Yes & 107 & 101 & \multirow{2}{*}{0.515} \\
\hline No & 10 & 13 & \\
\hline \multicolumn{4}{|c|}{ Pathological Stage } \\
\hline I & 13 & 16 & \multirow{4}{*}{0.425} \\
\hline II & 23 & 29 & \\
\hline III & 48 & 46 & \\
\hline IV & 33 & 23 & \\
\hline
\end{tabular}


Table 3. Cont.

\begin{tabular}{|c|c|c|c|}
\hline Patient Characteristics & LSR $\leqslant 0.80(n=117)$ & LSR > $0.80(n=114)$ & $p$-Value \\
\hline \multicolumn{4}{|c|}{ Lymph Node Metastasis (N) } \\
\hline No & 7 & 10 & \multirow{4}{*}{0.168} \\
\hline N1 & 22 & 16 & \\
\hline N2 & 74 & 82 & \\
\hline N3 & 14 & 6 & \\
\hline \multicolumn{4}{|c|}{ Distant Metastases } \\
\hline Yes & 94 & 98 & \multirow[b]{2}{*}{0.294} \\
\hline No & 23 & 16 & \\
\hline \multicolumn{4}{|c|}{ Tumor Location } \\
\hline Upper & 27 & 22 & \multirow{3}{*}{0.247} \\
\hline Middle & 35 & 26 & \\
\hline Lower & 55 & 66 & \\
\hline \multicolumn{4}{|c|}{ Maximum Tumor Diameter $(\mathrm{cm})$} \\
\hline$\leqslant 5$ & 65 & 79 & \multirow{2}{*}{0.041} \\
\hline$>5$ & 52 & 35 & \\
\hline \multicolumn{4}{|c|}{ Serous Infiltration } \\
\hline So & 16 & 28 & \multirow{4}{*}{0.055} \\
\hline S1 & 23 & 14 & \\
\hline S2 & 48 & 52 & \\
\hline S3 & 30 & 20 & \\
\hline & $\mathrm{ALB}(\mathrm{g} / \mathrm{L})$ & & \multirow{3}{*}{0.020} \\
\hline$\leqslant 35$ & 16 & 5 & \\
\hline$>35$ & 101 & 109 & \\
\hline & $\operatorname{ALT}(\mathrm{U} / \mathrm{L})$ & & \multirow{3}{*}{$<0.001$} \\
\hline$\leqslant 14.6$ & 94 & 20 & \\
\hline$>14.6$ & 23 & 94 & \\
\hline & AST (U/L) & & \multirow{3}{*}{0.004} \\
\hline$\leqslant 18.5$ & 70 & 46 & \\
\hline$>18.5$ & 47 & 68 & \\
\hline & $\mathrm{CRP}(\mathrm{mg} / \mathrm{L})$ & & \multirow{3}{*}{0.025} \\
\hline$\leqslant 1.56$ & 50 & 66 & \\
\hline$>1.56$ & 67 & 48 & \\
\hline & CA19-9 (U/mL) & & \multirow{3}{*}{0.008} \\
\hline$\leqslant 10.97$ & 49 & 68 & \\
\hline$>10.97$ & 68 & 46 & \\
\hline \multicolumn{4}{|c|}{ CA72-4 (U/mL) } \\
\hline$\leqslant 1.8$ & 61 & 55 & \multirow{2}{*}{0.600} \\
\hline$>1.8$ & 56 & 59 & \\
\hline \multicolumn{4}{|c|}{ CEA (ng/mL) } \\
\hline$\leqslant 2.17$ & 58 & 59 & \\
\hline$>2.17$ & 59 & 55 & 0.793 \\
\hline & $\mathrm{Fbg}(\mathrm{g} / \mathrm{L})$ & & \\
\hline$\leqslant 2.82$ & 57 & 59 & \\
\hline$>2.82$ & 60 & 55 & 0.694 \\
\hline & GPS & & \\
\hline 0 & 91 & 102 & \\
\hline 1 & 23 & 11 & 0.054 \\
\hline 2 & 3 & 1 & \\
\hline & p53 & & \\
\hline 0 & 23 & 33 & \\
\hline+1 & 42 & 33 & م075 \\
\hline+2 & 13 & 21 & 0.075 \\
\hline+3 & 39 & 27 & \\
\hline & Blood type & & \\
\hline A & 35 & 28 & \\
\hline $\mathrm{B}$ & 28 & 29 & 0736 \\
\hline $\mathrm{AB}$ & 9 & 7 & 0.736 \\
\hline $\mathrm{O}$ & 45 & 50 & \\
\hline
\end{tabular}




\section{Discussion}

Gastric cancer is the most common cancer and the second leading cause of cancer-related death in the world. Factors that may increase risk of gastric cancer include oxidative stress, DNA damage, Helicobacter pylori infection, and so on. Inflammation and H. Pylori infection induce oxidative stress, which leads to DNA damage, impairs immune function, extracellular signal-regulated kinase (ERK) activations and p53 over expression, which are related to cancer development [13].

The liver is the largest solid organ and plays a major role in metabolism with numerous functions in the human body. ALT and AST are the major critical enzymes in the biological processes [14]. The synthesized ALT and stored AST changes in serum levels have become diagnostic tools and markers for assessing the liver function [15]. Reports have suggested that their levels increase in different hepatic injures, such as hepatitis and cirrhosis induced by alcohol, drugs, viruses, and also under oxidative stress [16]. The liver could easily be exposed to internal stimuli which produce reactive oxygen species. The oxidative stress could damage the liver cells. The levels of ALT/AST in the serum have been generally accepted as a better predictor of liver injury [7]. Oxidative stress and inflammation are related to gastric cancer development; at the same time, oxidative stress and inflammation could also lead to damaged liver cells. With the development of tumor biology, there is growing evidence that the presence of a systemic inflammatory response is linked to poor survival in patients with different types of cancers $[17,18]$. Thus, our aim was to investigate the prognostic value of the preoperative LSR in patients with GA.

This study is mainly focused on the association between clinicopathological parameters and prognosis in gastric cancer. Previous studies have shown that serum albumin, CRP, TNM stage, serum globulin HER-2, CA72-4, and GPS were associated with OS in GC, and they could also predict prognostic factors for survival in gastric cancer $[9-11,17,19,20]$. In our study, only TNM stage, lymph node metastasis, distant metastases, tumor size, serous infiltration, ALB, LSR, CA72-4, Fbg, and p53 were shown to be predictors of OS in univariate analyses. However, the following multivariate analysis showed only LSR was independently associated with OS in patients with GA $(p=0.032)$, along with tumor stages $(p<0.001)$ and distant metastases $(p=0.019)$. Patients with LSR $\leqslant 0.80$ were associated with significantly worse survival than those with LSR $>0.80$. In our study, GPS and CRP were not as independent prognostic factors for survival in gastric cancer. We explained the results and the factors with $p$ values $<0.1$ in the univariate analysis were then performed using multivariate Cox regression analysis to identify independent predictors of OS. The factors we studied were more than other researchers did and the prognostic factors were more comprehensive.

Until now, many researchers have reported inflammation and oxidative stress were especially important for cancer progress. The reasons that inflammation and oxidative stress are related to gastric cancer is as follows: (1) tumor progression and metastasis comprise a cascade of steps which involve tumorigenic factors (inflammation, oxidative stress) which participate in the process [21-23]; (2) inflammatory and chronic oxidative stress leads to generating oxygen free radicals, which have been shown to stimulate cancer initiation, promotion, and progression [21]; (3) the gastrointestinal tract could easily be exposed to external and internal stimuli which produce ROS [24]; (4) systemic inflammation showed correlation with therapy response.

Serum transaminases were used to assess the stage of fibrosis, liver function, and prediction of prognosis for patients with chronic hepatitis [25]. Ronnie [26] reported an increased serum AST level was an independent adverse prognostic factor in patients with hepatocellular carcinoma associated with HBV-related cirrhosis. They considered the elevated transaminases were associated with hepatitis activity in the cirrhotic liver; this may increase the risk of recurrence. Shen [27] also found preoperative AST was an independent prognostic factor for hepatitis B-induced hepatocellular carcinoma after hepatic resection. Recent studies demonstrated that proliferating cancer cells show aerobic glycolysis, as well as increased glutamine metabolism, to maintain nucleotide biosynthesis and nonessential amino acids, which are catalyzed by transaminases [28,29]. The exact explanation for the decreased death rate in patients with a preoperatively-elevated ALT/AST ratio remain elusive. 
The major limitations of this study are as follows: (1) this study was a retrospective design, single-center site, and lacking measurements of $H$. pylori (HP) infection, since we could not obtain information from most studies regarding infection with HP, a strong risk factor for gastric cancer [30]; and (2) our study found that LSR was an independent prognostic factor in patients with GA, but we did not reveal the mechanisms of how LSR influences the patients' survival times. Further studies may aim at investigating what the role LSR plays in the prognosis of GA. Despite these limitations, we report the first study of the potential prognostic value of the preoperatively-evaluated LSR in patients of gastric cancer.

In recent years, "liquid biopsies" have attracted increasing interest for noninvasive cancer diagnosis, prognostis, and monitoring of treatment response. Several studies have provided proof-of-principle data related to several circulating markers that could be used for cancer prognosis. These blood-based biomarkers include circulating tumor cells, DNA-, RNA-, and protein-based markers. We evaluated the association between the circulating protein-based markers and survival in GA and found LSR was an independent predictor of poor survival in GA, thus, it is a new prognostic marker in gastric cancer.

In conclusion, our first report LSR was an independent predictor of poor survival in gastric cancer. The following study programs should validate this association and elucidate the mechanisms by which LSR affects the risk of prognosis in gastric cancer. In a word, preoperative serum LSR is a simple, convenient, and low-cost prognostic marker in gastric adenocarcinoma patients undergoing curative treatment.

\section{Materials and Methods}

\subsection{Patients}

A total of 231 histologically-proven gastric adenocarcinoma patients at the Sun Yat-sen University Cancer Center who were treated with undergoing curative treatment from 2008 to 2015 were enrolled in this study. Collection and recording of the patient's clinical data, including sex, age, smoking, family history, location, $\mathrm{ABO}$ blood group, tumor size, serous infiltration, lymph node metastasis, CA72-4, CA19-9, CEA, ALB, C-reactive protein, p53, ALT, AST, ALT/AST, Fibrinogen (Fbg), GPS score, TNM stage, diagnosis, treatment, and follow-up results was conducted. All procedures performed were in accordance with the ethical standards of the national regulations and with the 1964 Helsinki Declaration and its later amendments. Our study was approved by the Sun Yat-sen University Cancer Center research ethics committee. The study was approved by the Ethics Committee of Sun Yat-Sen University Cancer Center, and all patients signed an informed consent before inclusion in the study. The inclusion criteria as following: (1) all patients were histologically confirmed as having stage I to IV adenocarcinoma of the stomach depending on postoperative histological specimen; (2) clinical data were complete; (3) good performance status; (4) undergoing curative treatment; (5) patients with other malignant tumors; and (6) no liver dysfunction. All patients were followed up until death or 30 October 2015, if still alive.

\subsection{Laboratory Measurements}

Fbg was measured by coagulation method using Sysmex CA7000 System (Sysmex, Kobe, Japan). ALT, AST, ALB, CRP were measured by Hitachi 7600 Automatic Analyzer (Tokyo, Japan). CA19-9, CA72-4, CEA were measured using electrochemiluminescence immunoassay (Roche COBAS-E-602, Shanghai, China). The value of Fbg, ALT, AST, ALB, CRP, CA19-9, CA72-4, CEA testing one day before pre-operation was recorded. The LSR was defined as the serum ALT level divided by the serum AST level. The GPS was calculated by CRP and ALB using standard thresholds $(>10 \mathrm{mg} / \mathrm{L}$ for CRP and $\leqslant 35 \mathrm{~g} / \mathrm{L}$ for ALB). Patients with both a CRP level $>10 \mathrm{mg} / \mathrm{L}$ and an ALB level $\leqslant 35 \mathrm{~g} / \mathrm{L}$ were categorized as having a score of 2 . Patients with only one of these abnormalities were categorized as having a score of 1 . Patients with neither of these abnormalities were categorized as having 
a score of 0 [31]. p53 evaluation was carried out according to the data available in the literature [32]. Accordingly, they were assigned scores of $0,+1,+2$, and +3 according to their immune-reactivity.

\subsection{Statistical Analysis}

Data was summarized with the number of subjects and mean value, and the cutoff value of preoperative Fbg, ALT, AST, CRP, CA19-9, CA72-4, CEA, and LSR were estimated by median. Overall survival (OS) was calculated from the date of surgery to the date of death or last follow-up. Statistical analysis was performed by SPSS software, version 19.0 (SPSS Inc., Chicago, IL, USA). The Chi-square test was used to compare categorical variables. Multivariate Cox regression was used to perform survival analysis in order to estimate the variables for survival. Results of the Cox regression analyses were reported with hazard ratios (HR), together with the corresponding 95\% confidence intervals (CI). Survival curves were constructed according to the Kaplan-Meier method and compared using the log-rank test. All factors significant in univariate analyses were entered into a multivariate analysis. Two-tailed $p$ values $<0.05$ were considered significant.

Acknowledgments: We thank the staff at the Director of Clinical Laboratories, Sun Yat-sen University Cancer Center for providing support on research conditions in this study.

Author Contributions: Conceived and designed the experiments: Xia He. Performed the experiments: Shu-Lin Chen. Analyzed the data: Jian-Pei Li. Contributed reagents/materials/analysis tools: Lin-Fang Li, Tao Zeng. Wrote the paper: Shu-Lin Chen. Informed consent was obtained from all individual participants included in the study.

Conflicts of Interest: The authors declare no conflict of interest.

\section{References}

1. Jemal, A.; Bray, F.; Center, M.M.; Ferlay, J.; Ward, E.; Forman, D. Global cancer statistics. CA A Cancer J. Clin. 2011, 61, 69-90. [CrossRef] [PubMed]

2. Yamaoka, Y.; Kato, M.; Asaka, M. Geographic differences in gastric cancer incidence can be explained by differences between Helicobacter pylori strains. Intern. Med. (Tokyo Jpn.) 2008, 47, 1077-1083. [CrossRef]

3. Thrumurthy, S.G.; Chaudry, M.A.; Hochhauser, D.; Mughal, M. The diagnosis and management of gastric cancer. BMJ 2013, 347. [CrossRef] [PubMed]

4. Karmen, A.; Wroblewski, F.; Ladue, J.S. Transaminase activity in human blood. J. Clin. Investig. 1955, 34, 126-133. [CrossRef] [PubMed]

5. Pratt, D.S.; Kaplan, M.M. Evaluation of abnormal liver-enzyme results in asymptomatic patients. N. Engl. J. Med. 2000, 342, 1266-1271. [CrossRef] [PubMed]

6. Jamali, R.; Pourshams, A.; Amini, S.; Deyhim, M.-R.; Rezvan, H.; Malekzadeh, R. The upper normal limit of serum alanine aminotransferase in Golestan province, northeast Iran. Arch. Iran. Med. 2008, 11, $602-607$. [PubMed]

7. $\quad$ Lin, M.-S.; Lin, H.-S.; Chung, C.-M.; Lin, Y.-S.; Chen, M.-Y.; Chen, P.-H.; Hu, J.-H.; Chou, W.-N.; Huang, J.-C.; Huang, T.-J. Serum aminotransferase ratio is independently correlated with hepatosteatosis in patients with HCV: A cross-sectional observational study. BMJ Open 2015, 5, e008797. [CrossRef] [PubMed]

8. Zang, J.-P.; Wang, H.-B.; Lin, Y.-H.; Xu, J.; Wang, J.; Wang, K.; Liu, W.-L. Lactate dehydrogenase is an important prognostic indicator for hepatocellular carcinoma after partial hepatectomy. Transl. Oncol. 2015, 8, 497-503.

9. Onate-Ocana, L.F.; Aiello-Crocifoglio, V.; Gallardo-Rincon, D.; Herrera-Goepfert, R.; Brom-Valladares, R.; Carrillo, J.F.; Cervera, E.; Mohar-Betancourt, A. Serum albumin as a significant prognostic factor for patients with gastric carcinoma. Ann. Surg. Oncol. 2007, 14, 381-389. [CrossRef] [PubMed]

10. Liu, X.; Sun, X.; Liu, J.; Kong, P.; Chen, S.; Zhan, Y.; Xu, D. Preoperative C-reactive protein/albumin ratio predicts prognosis of patients after curative resection for gastric cancer. Transl. Oncol. 2015, 8, 339-345. [CrossRef] [PubMed] 
11. Chen, J.; Zhou, Y.; Xu, Y.; Zhu, H.-Y.; Shi, Y.-Q. Low pretreatment serum globulin may predict favorable prognosis for gastric cancer patients. Tumor Biol. 2015, 37, 1-7. [CrossRef] [PubMed]

12. Chung, L.; Moore, K.; Phillips, L.; Boyle, F.M.; Marsh, D.J.; Baxter, R.C. Novel serum protein biomarker panel revealed by mass spectrometry and its prognostic value in breast cancer. Breast Cancer Res. 2014, 16. [CrossRef] [PubMed]

13. Li, X.; Fang, P.; Mai, J.; Choi, E.T.; Wang, H.; Yang, X. Targeting mitochondrial reactive oxygen species as novel therapy for inflammatory diseases and cancers. J. Hematol. Oncol. 2013, 6. [CrossRef] [PubMed]

14. Shakoori, A.; Butt, U.; Riffat, R.; Aziz, F. Haematological and biochemical effects of danitol administered for two months in the blood and liver of rabbits. Z. Feur Angew. Zool. 1994, 80, 165-180.

15. Onyesom, I.; Anosike, E. Changes in rabbit liver function markers after chronic exposure to ethanol. Asian J. Biochem. 2007, 2, 334-342.

16. Navarro, M.C.; Montialla, M.; Martín, A.; Jiménez, J.; Utrilla, M.P. Free radical scavenger and antihepatotoxic activity of Rosmarinus tomentosus. Planta Med. 1993, 59, 312-314. [CrossRef]

17. Toiyama, Y.; Inoue, Y.; Saigusa, S.; Kawamura, M.; Kawamoto, A.; Okugawa, Y.; Hiro, J.; Tanaka, K.; Mohri, Y.; Kusunoki, M. C-reactive protein as predictor of recurrence in patients with rectal cancer undergoing chemoradiotherapy followed by surgery. Anticancer Res. 2013, 33, 5065-5074. [PubMed]

18. Park, J.H.; Watt, D.G.; Roxburgh, C.S.; Horgan, P.G.; McMillan, D.C. Colorectal cancer, systemic inflammation, and outcome: Staging the tumor and staging the host. Ann. Surg. 2016, 263, 326-336. [CrossRef] [PubMed]

19. Uprak, T.K.; Attaallah, W.; Çelikel, Ç.A.; Ayranc1, G.; Yeğen, C. HER-2 incidence in gastric cancer, its association with prognosis and clinicopathological parameters. Turk. J. Surg. Ulus. Cerrahi. Derg. 2015, 31, 207-213.

20. Sun, Z.; Zhang, N. Clinical evaluation of CEA, CA19-9, CA72-4 and CA125 in gastric cancer patients with neoadjuvant chemotherapy. World J. Surg. Oncol. 2014, 12, 1-12. [CrossRef] [PubMed]

21. Gopal, K.; Gupta, N.; Zhang, H.; Alshareef, A.; Alqahtani, H.; Bigras, G.; Lewis, J.; Douglas, D.; Kneteman, N.; Lavasanifar, A. Oxidative stress induces the acquisition of cancer stem-like phenotype in breast cancer detectable by using a Sox2 regulatory region-2 (SRR2) reporter. Oncotarget 2015, 7, 3111-3127.

22. Falfushynska, H.; Gnatyshyna, L.; Deneha, H.; Osadchuk, O.; Stoliar, O. Manifestations of oxidative stress and molecular damages in ovarian cancer tissue. Ukr. Biochem. J. 2015, 87, 93-102. [CrossRef] [PubMed]

23. Coussens, L.M.; Werb, Z. Inflammation and cancer. Nature 2002, 420, 860-867. [CrossRef] [PubMed]

24. Szkandera, J.; Pichler, M.; Absenger, G.; Stotz, M.; Arminger, F.; Weissmueller, M.; Schaberl-Moser, R.; Samonigg, H.; Kornprat, P.; Stojakovic, T. The elevated preoperative platelet to lymphocyte ratio predicts decreased time to recurrence in colon cancer patients. Am. J. Surg. 2014, 208, 210-214. [CrossRef] [PubMed]

25. Lin, Z.H.; Xin, Y.N.; Dong, Q.J.; Wang, Q.; Jiang, X.J.; Zhan, S.H.; Sun, Y.; Xuan, S.Y. Performance of the aspartate aminotransferase-to-platelet ratio index for the staging of hepatitis C-related fibrosis: An updated meta-analysis. Hepatology 2011, 53, 726-736. [CrossRef] [PubMed]

26. Poon, R.T.-P.; Fan, S.-T.; Lo, C.-M.; Liu, C.-L.; Ng, I.O.-L.; Wong, J. Long-term prognosis after resection of hepatocellular carcinoma associated with hepatitis B-related cirrhosis. J. Clin. Oncol. 2000, 18, 1094-1101. [PubMed]

27. Shen, S.-L.; Fu, S.-J.; Chen, B.; Kuang, M.; Li, S.-Q.; Hua, Y.-P.; Liang, L.-J.; Guo, P.; Hao, Y.; Peng, B.-G. Preoperative aspartate aminotransferase to platelet ratio is an independent prognostic factor for hepatitis B-induced hepatocellular carcinoma after hepatic resection. Ann. Surg. Oncol. 2014, 21, 3802-3809. [CrossRef] [PubMed]

28. Yang, C.; Sudderth, J.; Dang, T.; Bachoo, R.G.; McDonald, J.G.; de Berardinis, R.J. Glioblastoma cells require glutamate dehydrogenase to survive impairments of glucose metabolism or Akt signaling. Cancer Res. 2009, 69, 7986-7993. [CrossRef] [PubMed]

29. Cairns, R.A.; Harris, I.S.; Mak, T.W. Regulation of cancer cell metabolism. Nat. Rev. Cancer 2011, 11, 85-95. [CrossRef] [PubMed]

30. Kim, M.J.; Kim, H. Anticancer effect of lycopene in gastric carcinogenesis. J. Cancer Prev. 2015, $20,92-96$. [CrossRef] [PubMed] 
31. Forrest, L.; McMillan, D.; McArdle, C.; Angerson, W.; Dunlop, D. Evaluation of cumulative prognostic scores based on the systemic inflammatory response in patients with inoperable non-small-cell lung cancer. Br. J. Cancer 2003, 89, 1028-1030. [CrossRef] [PubMed]

32. Cruz, I.; Napier, S.; van der Waal, I.; Snijders, P.; Walboomers, J.; Lamey, P.; Cowan, C.; Gregg, T.; Maxwell, P.; Meijer, C. Suprabasal p53 immunoexpression is strongly associated with high grade dysplasia and risk for malignant transformation in potentially malignant oral lesions from Northern Ireland. J. Clin. Pathol. 2002, 55, 98-104. [CrossRef] [PubMed]

(C) 2016 by the authors; licensee MDPI, Basel, Switzerland. This article is an open access article distributed under the terms and conditions of the Creative Commons Attribution (CC-BY) license (http://creativecommons.org/licenses/by/4.0/). 